\title{
REVISIONES
}

\section{La educación pública en la encrucijada: la pérdida del sentido público de la escolaridad*}

Public education at the crossroads: the loss of the sense of public education

A educação pública na encruzilhada: a perda do sentido público da escolaridade

\author{
Félix Angulo Rasco, ${ }^{a}$ Silvia Redon Pantoja ${ }^{b}$ \\ âniversidad de Cádiz, España. Correo electrónico: felix.angulo@uca.es \\ bUniversidad Católica de Valparaíso, Chile. Correo electrónico: silvia.redon@gmail.com
}

\begin{abstract}
RESUMEN
El trabajo que se presenta tiene por objetivo analizar las políticas educativas neoliberales y mercantilistas que están situando a la escolaridad pública en una encrucijada que puede llevarla a su desaparición. Para ello, y en primer lugar, expondremos el marco posible -los códigos- necesario para comprender, en su contexto, la política económica -el neoliberalismo- que ha hecho que llegásemos a la situación actual. En segundo lugar, intentaremos identificar en un sentido muy primario, pero esencial, qué es lo público y qué significa. En tercer lugar, expondremos con cierto detalle las variantes que ha adoptado la mercantilización de la educación y las consecuencias nefastas que de ellas se derivan para el futuro inmediato de la educación pública.
\end{abstract}

Palabras clave: escuela pública, políticas neoliberales, mercantilismo.

\begin{abstract}
The paper has the aim to analyze the neoliberal and mercantilist educational policies that are placing public education and schooling at a crossroads, which can lead to its demise. To do this, and firstly, we discuss the possible framework -codes- needed to understand, in context, the economic policy -neoliberalism- that has helped to reach the current situation. Second, we try to identify a very simple but essential sense to what is public and what it means. Third, we will discuss in some detail, the variants that have adopted the commodification of education and the disastrous consequences that flow from them, for the immediate future of public education.
\end{abstract}

Key words: public education, public schools, neoliberal politics, mercantilism.

\section{RESUMO}

Objetiva-se analisar as políticas neoliberais e mercantilistas da educação, as quais situam a escola pública em uma encruzilhada, ocoasianando o desaparecimento de ela. Para isso, expõe-se primeiramente o marco possível, os códigos - necessários à compreensão, em seu contexto, da política econômica e o neoliberalismo - responsável pela atual situação. Em segundo lugar, tenta-se identificar um sentido primário, mas essencial à compreensão do que é público e de seus significados. Por fim, expõe-se detalhadamente as variantes adotadas pela mercantilização da educação e as nefastas consequências que daí se derivam em um futuro imediato da educação pública.

Palavras chave: escola pública, políticas neoliberais, mercantilismo.

* Este artículo fue solicitado por la Revista Estudios Pedagógicos en diciembre del 2011 en el contexto del proyecto de Investigación FONDECYT (Fondo de Investigación Científica y Tecnológica) No 11110016 , titulado "Educación Física y su función de transformación de las desigualdades sociales: profesorado del área y documentación ministerial”. El artículo fue aceptado en junio de 2012. 


\section{INTRODUCCIÓN}

Puede parecer una alarma infundada y excesiva afirmar que la escuela pública se encuentra en una encrucijada histórica que puede suponer para ella, si no su desaparición total, sí su reducción a una mera anécdota social. Siendo un 'invento' relativamente reciente (Boli, Ramírez y Meyer 1990; Angulo 2011; Meyer et al., 1992), nos acostumbramos pronto a su presencia como parte de nuestros ritos sociales y de los hijos y las hijas de miles de familias en todo el mundo. No podemos dudar de que ha tenido momentos claramente expansivos -hasta los sesenta en muchos países desarrollados- y que, de una manera u otra, se ha extendido, como un modo de isomorfismo institucional (Boli et al., 1990; Rowan y Miskel, 1999) en sociedad distintas y distantes. Sin embargo, desde finales de los años setenta, la presencia y el sentido de la escolaridad pública se encuentra en claro declive; un declive que se ha visto acentuado y enfatizado por fuerzas contrarias a ella y a todo lo que tenga que ver con lo público, o dicho de otra manera, lo común y lo ciudadano.

Aceptamos que nuestro alarmismo tiene un límite: la escuela pública no ha desparecido por completo; pero, y éste es uno de los objetivos del presente trabajo, creemos que el período de crisis y desconcierto político-económico mundial que vivimos, la sitúan como nunca antes al borde del abismo. En lo que sigue queremos mostrar las razones que justifican nuestra preocupación. En primer lugar, expondremos el marco posible para comprender, en su contexto, la política económica -el neoliberalismo- que ha hecho que llegásemos a la situación actual. En segundo lugar, intentaremos identificar un sentido muy primario pero esencial de lo público. En tercer lugar, expondremos con cierto detalle las variantes que ha adoptado la mercantilización de la educación y las consecuencias nefastas que de ellas se derivan para el futuro inmediato de la educación pública.

\section{LOS CÓDIGOS DE LA ECONOMÍA POLÍTICA ACTUAL}

Pues hay una cosa que quisiera notar particularmente aquí, a saber: que nosotros no podemos, por decisión del alma hacer nada que previamente no recordemos. Por ejemplo, no podemos decir una palabra, si no nos acordamos de ella Baruch de Espinosa, Ética

No se le escapará a cualquier analista avezado que, en la economía política, los términos genéricos que empleamos para referirnos a las situaciones o a las mismas opciones políticas han ido cambiando en los últimos 40 años. Actualmente resulta complicado encontrar el término 'capitalismo' en los textos en los que se supone que se habla de él y aún menos en nuestro vocabulario; incluso 'neoliberalismo', un término ampliamente utilizado entre los ochenta y los noventa fue rápidamente substituido por el de globalización, que, a su vez, ha desaparecido también, tapado por una conjunto de términos como mercados financieros, ajustes fiscales o control del déficit. A pesar de estos cambios, no hemos dejado de ser capitalistas, ni el neoliberalismo ha cesado, ni la globalización ha pasado a mejor vida. Los vaivenes terminológicos parecen tener una razón ideológica: hacernos 
creer que vivimos situaciones radicalmente novedosas, que están evolucionando y que no tienen conexión con el pasado. Estamos tentados de afirmar que estas sustituciones y mutaciones terminológicas parece que lo que pretenden es que no pensemos con claridad y que no entendamos que nos encontramos en un período de un capitalismo duro y hasta despiadado, que tiene más que ver, en algunos aspecto sociales y laborales con el capitalismo salvaje de finales del XIX ${ }^{1}$ que con el de la postguerra europea. Una manera de resituar los términos está en cambiar el enfoque y apartarnos de la mera terminología. El que aquí proponemos está relacionado con el empleo de códigos de regulación. Este enfoque se sustenta en la teoría regulacionista de la economía, elaborada originalmente por Aglietta (1979), Boyer (1992) y Lippietz (1986), pero también en la idea de código de regulación, planteada tempranamente por Gramsci (1980). ${ }^{2}$

La ventaja de utilizar códigos es que nos permiten analizar con detalle y situar los acontecimientos históricos y las tendencias predominantes. En última instancia, lo que quiere dar cuenta el enfoque regulacionista es del hecho de que el régimen de acumulación capitalista es un acontecimiento de regulación que se expresa en distintas esferas institucionales a través de diversos procesos de flexibilización, de reestructuración o, por el contrario, de regulación extrema, que se atienen a códigos particulares en cada ámbito institucional. No comprenderemos el sentido de los cambios que están ocurriendo si nos quedamos únicamente en los niveles inferiores de los acontecimientos; necesitamos construir un mapa de los códigos de explicitación, al menos para comprender las derivaciones distintas que pueden convivir en un momento dado.

No es nuestra intención señalar todas las posibilidades de este enfoque y mucho menos de explicitar minuciosamente los detalles de un acontecimiento tan complejo como las 'sociedades modernas' (y por extensión 'la modernidad'). Nos basta, para nuestros propósitos, aceptar que las sociedades modernas son el producto de ciertas dimensiones institucionales $^{3}$ (Giddens, 1993), que conforman cuatro ámbitos o dimensiones de organización institucional.

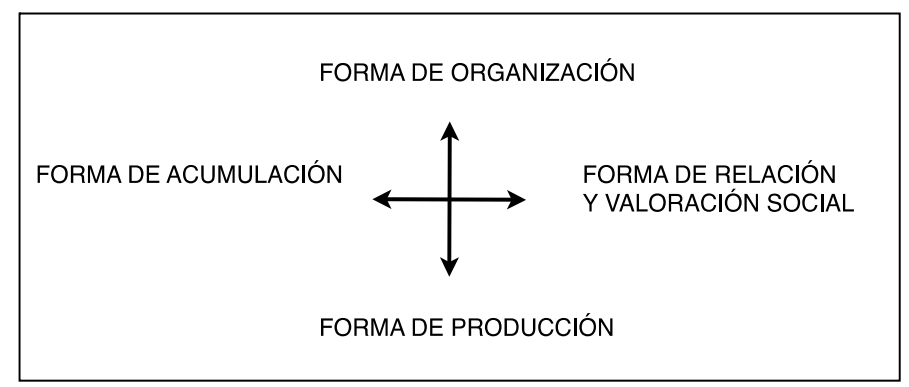

Figura 1. Fuente: Elaboración propia tomando como referencia Giddens (1990)

\footnotetext{
1 Tenemos en mente el capitalismo de la primera y segunda revolución industrial. Véase Hobsbawn (2003, 2004).

2 Aplicada por Harvey (1989) a los cambios políticos.

3 Esta idea es deudora de la definición de forma institucional que emplea Boyer (1992: 54): "Se definirá así como forma institucional (o también estructura) toda codificación de una o varias relaciones sociales fundamentales.
} 
Tomemos, pues, las cuatro dimensiones que hemos señalado, de derecha a izquierda. La primera hace referencia al modo en que las sociedades se organizan; la segunda, a la manera en que crean o atesoran sus riqueza; la tercera, a la generación y producción de bienes necesarios para vivir; la última, señala tanto la cosmovisión valorativa como el o los sistemas con los que los grupos sociales se dotan para organizar lo que Habermas (1973) denominaba 'conformación de la voluntad política'. La tesis que mantenemos es que la sociedad moderna y el mundo capitalista que surge de la segunda guerra mundial, se estructura a través de unos códigos concretos; códigos que comienzan a ser sustituidos, con diversa velocidad, a partir de los años ochenta. Detengámonos ahora en la tabla resumen siguiente; en la segunda columna hemos señalado los códigos que han funcionado en nuestras sociedades hasta, como decíamos, al menos finales de los años 70. Se trata de unos códigos que sustentaron el desarrollo, con las variantes conocidas, del estado de bienestar y de una sociedad que alcanzó una prosperidad general, nunca conocida antes. En la tercera columna, se indican los nuevos códigos que comenzaron a ser invocados (segunda modernidad) ${ }^{4}$, propuestos y defendidos por los gobiernos neoliberales que lograron el poder a finales de los setenta y principios de los ochenta, especialmente en el Reino Unido y en los Estados Unidos de Norteamérica.

\begin{tabular}{|c|c|c|}
\hline $\begin{array}{c}\text { DIMENSIONES } \\
\text { INSTITUCIONALES }\end{array}$ & $\begin{array}{c}\text { CÓDIGOS DE LA } \\
\text { MODENIDAD }\end{array}$ & $\begin{array}{c}\text { CÓDIGOS DE LA SEGUNDA } \\
\text { MODERNIDAD } \\
\text { (GLOBALIZACIÓN) }\end{array}$ \\
\hline Organización & Regulación del Bienestar & $\begin{array}{c}\text { Regulación Flexible } \\
\text { (Desregulación Supranacional) }\end{array}$ \\
\hline Acumulación & $\begin{array}{c}\text { Economía de Bienestar } \\
\text { ('Capitalismo Regulado') }\end{array}$ & $\begin{array}{c}\text { Mercado Global (Economía } \\
\text { Financiera) }\end{array}$ \\
\hline Producción & Industrialismo & Producción Flexible \\
\hline $\begin{array}{c}\text { Valoración y Relación } \\
\text { Social }\end{array}$ & $\begin{array}{c}\text { Ciudadanía/ } \\
\text { Democracia Representativa }\end{array}$ & $\begin{array}{c}\text { Consumidor } \\
\text { (Democracia limitada) }\end{array}$ \\
\hline
\end{tabular}

Tabla 1. Dimensiones institucionales y códigos. Fuente: Elaboración Propia

La primera columna, como decíamos, puede resultar bastante evidente. La regulación de bienestar y la economía de bienestar implican la existencia de un mínimo de estado de bienestar, que asume los derechos sociales de sus ciudadanos en cuanto derechos; es decir, un estado que a través de políticas keynesianas y de una política fiscal redistributiva, mantiene sistemas sociales como el de sanidad y la educación, básicos para la ciudadanía. Como nos ha recordado Muñoz del Bustillo (1989: 25),

4 Hemos optado por la denominación Primera y Segunda Modernidad, como un punto neutral con respecto a la enorme y varia terminología empleada en la literatura política al uso. 
"la aceptación de los principios keynesianos de política presupuestaria tiene el efecto de crear una 'base económica' que permite la actuación del estado en múltiples áreas del funcionamiento de la sociedad. La política keynesiana es así... central al Estado de Bienestar, no tanto que garante del pleno empleo..., sino en cuanto que aumenta... el techo de intervención económica del estado, sin el cual la política social se convertiría en meramente testimonialista".

El capitalismo aceptó un cierto grado de regulación y un sistema impositivo y fiscal importante y necesario, en orden a mantener los derechos básicos. Aunque el código del industrialismo fue uno de los que primero apareció, aquí representa la idea de un cambio, por así decir, de una situación de subsistencia a otra de bienestar; de un sistema productivo cotidiano a otro en el que es posible desarrollar una sólida clase media. La presencia creciente, como sector productivo, del sector de servicios, conectado con los derechos básicos de sanidad, educación, desarrollo cultural y protección, tienen aquí un papel predominante.

En resumen, la intervención estatal y la regulación del mercado, por parte del estado, tenía como objetivo acercarse al pleno empleo y apoyar una economía de la demanda. Además, las administraciones ofrecieron una provisión estatal de servicios universales, como sanidad, educación, vivienda, desempleo, pensiones, ayudas familiares y protección social; aceptando, con ello, la obligación y responsabilidad pública del sostenimiento de un nivel mínimo de vida, diferente a los mecanismo de caridad, como elemento constitutivo de responsabilidad colectiva de todos los ciudadanos y ciudadanas. (Mishra, 1992). La idea de ciudadanía no era una cuestión sólo de participación en la vida política, sino también de participación en el bienestar, de derechos básicos.

Como resultado, es fácil aceptar que una situación de estado de bienestar genera y distribuye, más o menos equitativamente, bienes culturales e intelectuales, además de la satisfacción de necesidades básicas primordiales, que confieren a una amplia mayoría posibilidades políticas y sociales impensables en otra situación. Esa amplia mayoría es la que constituye, definitivamente, la clase media; una clase formada, relativamente ilustrada y, lo que parece más interesante, dispuesta a participar en la vida política y económica haciendo uso de los mecanismos democráticos y de bienestar disponibles. Podríamos afirmar, simplificando probablemente en exceso, que a finales de los años setenta, encontramos una economía capitalista asentada y protegida, una industrialización extendida, una estructura administrativa amplia y ramificada, una democracia liberal triunfante y una clase media imperante como formación social.

Sin embargo, es desde principios de los años setenta cuando comienza a percibirse serias quiebras que atañen a los códigos que han estado vigentes hasta ese momento (Albarracín, 1991; Navarro, 1997; Steger y Roy, 2011). No es fácil señalar cada punto de inflexión y cada extremo de la crisis que comenzó por esas fechas a mostrarse como algo palpable y evidente. Si nos situamos en el plano meramente económico, algunos señalarán a la subida de los precios del petróleo como desencadenante de las mismas. Pero, en realidad, como ha demostrado Albarracín (1991), no es aquí en donde el problema se encuentra, porque el problema es múltiple.

En principio, y sin abandonar el plano económico, se trata de una disminución de la tasa de ganancia/beneficio en la dimensión acumulativa (i.e. una crisis de acumulación) (Aglietta, 1979). Las políticas económicas keysesianas se criticará desde sectores conservadores en alza, tendientes a crear más problemas que soluciones y a introducir disfunciones en la lógica inmanente del desarrollo económico, político y social (Friedman 
y Friedman, 1980). Los Estados de Bienestar, se dirá, no son más que generadores de déficit fiscal, provocado por un afán redistributivo que no puede compadecerse y saciar las crecientes demandas sociales generadas por él mismo en la ciudadanía, por más que aumente el sistema impositivo (Buchanan y Wagner, 1983). Como complemento, su excesivo intervencionismo en la economía -debido a la expansión del sector público y la adopción de estructuras típicas de mercado, y su hipertrofiada legislación 'regulacionista' en la producción, generó, se añadía, una profunda alteración en las condiciones de acumulación del capital (Mishra, 1992; Allen, 1992), aumentado hasta grados insostenibles para el capital los costes salariales, las atribuciones alcanzadas por los sindicatos y, en fin, ha hecho más patente la supuesta ineficacia e inoperancia del sector público en su conjunto. Al fin y al cabo, se añadirá como colofón de las críticas reseñadas, el Estado de Bienestar está moribundo porque aunque permitió el desarrollo individual de los ciudadanos y de las sociedades modernas, ha llegado a un punto en que está provocando lo contrario: la paralización, desincentivación y el inmovilismo de la iniciativa individual y de la inversión privada. Las consecuencias son triples aunque entrelazadas en una red contradictoria: el desorbitado déficit fiscal de las arcas públicas, el paro y la inflación. ${ }^{5}$ La respuesta, se añadirá desde los think tanks y los economistas neoliberales, no puede ser otra que la de volver a situar la primacía del individuo allí donde surgió: en el mercado (Friedman y Friedman, 1980; Buchanan y Wagner, 1983; Hayek, 1985). ${ }^{6}$ Pero la entronización de la ideología social del mercado como motor de superación de la crisis acarrea serios y significativos cambios en el paisaje y, a fortiori, en los códigos vigentes, que, al mismo tiempo, se apoyan en los cambios internos emergentes. Veamos algunos de estos cambios.

La vía experimentada parcial o totalmente por las economías de los países avanzados, para salir del dilema material entre desempleo e inflación, déficit público y constreñimiento de la inversión, ha sido una especie de mezcla entre economía monetarista y economía de oferta. Se ha pretendido reforzar las fuerzas del mercado, libres de la mano visible del estado, devolviendo a la iniciativa privada lo que supuestamente, se le había sustraído. Los nuevos lemas de 'privatización, 'estado ligero', desregulación', 'productividad sin excedentes' y otros por el estilo vienen a substituir a los que el estado de bienestar había legitimado, ahora obsoletos (Harvey, 1989; Allen, 1992; Salaman, 1992; Braham, 1992; Mishra, 1992; Navarro, 1997; Steger y Roy, 2011).

La sobreestimación del mercado ha supuesto, en la mayoría de los casos, el desmantelamiento del estado de bienestar. La desregulación conlleva la liberalización de la contratación laboral y del 'mercado de trabajo', dejando de ser el estado un intermediaro/ protector en la misma, la privatización de sectores económicos claramente productivos (i.e. telecomunicaciones, petróleo, 'banca nacional', etc.). ${ }^{7}$

No obstante, la 'reducción' del estado tiene sus límites; límites marcados por responsabilidades públicas intransferibles y por todos conocidas. La reducción debida en parte a la privatización directa, se extiende más allá hasta la asimilación en el funcionamiento

5 Esta retórica proveniente de los años ochenta, es mutatis mutandis, la misma que encontramos actualmente en el discurso de la Comisión Europea. Véase Bruno, Clément y Laval (2010).

6 Véase también Steger y Roy (2011), para una visión no sólo histórica, sino equilibrada de la política neoliberal y del papel de las Instituciones y Fundaciones promotoras, difusoras y defensoras del neoliberalismo.

7 En España las Cajas de Ahorro, que difieren de los Bancos tradicionales en que no tienen que distribuir dividendos, sino dedicar las ganancias a servicios sociales, comenzaron un proceso lento pero paulatino de privatización de la mano del anterior gobierno socialdemócrata, que el actual -conservador- concluirá. 
de la administración pública del 'espíritu empresarial' (Osborne y Glaeber, 1994; Steger y Roy, 2011). Al igual que las empresas, los cambios tienen que ver con la desregulación de los procesos, pero no con los objetivos y valores para los cuales han sido erigidas. Los estados dejan de ser proveedores de bienes-servicios, pero, como pseudo-empresarios, acumulan el poder de decidir y controlar los objetivos que han de ser alcanzados, allí donde su transferencia no resulta recomendable para nadie y menos para el capital. Utilizando una expresión de Osborne y Gaebler (1994), asimilar el espíritu empresarial supone aquí también controlar el timón, dejando que sean otros los que remen. Es decir, se separa la toma de decisiones políticas de la prestación del servicio y de la acción. Con ello se espera reducir costos, animar a la competitividad y fomentar la iniciativa tanto en las organizaciones públicas y en las comunidades sujeto de los servicios como en las organizaciones privadas que asumen las prestaciones disponibles.

Esta conversión empresarial del sector público, con el equívoco mensaje de la reducción de dicho sector y el falso lema de la descentralización, ha provocado precisamente el reforzamiento del estado. Paradójicamente, aunque los aparatos gubernamentales han llegado a ser 'menores', se ha incrementado su poder de control. Podría pensarse que se ha invertido la dicotomía que distinguió a los imperios de los estados naciones; si estos últimos se consolidaron por su mayor capacidad infraestructural y su menor potencial despótico; su evolución está significando una lenta, pero imparable, renuncia infraestructural a un aumento visible de sus posibilidades despóticas. Como demostró Gamble (1994) en la Inglaterra thatcherista, una 'economía libre' y una 'ideología social de mercado' conjugan muy bien con un estado y, por añadidura, con organizaciones supranacionales fuertes.

Las consecuencias han sido amplias y palpables en la vida política de los países desarrollados:

1) las tendencias a la conversión empresarial del estado están afectando y afectarán, a todas las competencias de la 'administración pública', porque afecta al concepto mismo de lo público. El sistema educativo no ha quedado exento de tales influencias (Witty, 1997; Witty, Power y Halpin, 1999; Laval, 2005).

2) Centrarse en el control de los objetivos y del 'timón', acarrea, casi de forma inevitable, la consolidación de élites informadas; élites que no están dispuestas a compartir su capacidad de decisión sustantiva ni su 'responsabilidad de control, sustrayendo a la discusión y debate público de sus iniciativas. Ambas consecuencias afectan a la democracia, porque afectan a la capacidad de los ciudadanos para participar, como decíamos en la conformación de la voluntad política.

3) El uso sostenido en el lenguaje político y en los responsables de la administración del vocablo 'cliente' implica un cambio de mentalidad trascendente. Si la idea de ciudadano ha estado íntimamente ligada a la democracia y al surgimiento del espacio público; la pérdida de dicho espacio, su disolución por el empuje y realización de las nuevas tendencias, está cambiando incluso los términos mismos del 'contrato social' con y entre los individuos. Asistimos a una profunda transformación de la aceptación de derechos y obligaciones con y de los ciudadanos en razón de su ciudadanía, a la aceptación de derechos y obligación en razón de su acceso al mercado, es decir, a la compra y venta de servicios por quien puede, el cliente, comprarlos a quien los vende.

Aquí encontramos la entronización de un elemento clave del mismo capitalismo, que en su día MacPherson (1970) denominó el 'individualismo posesivo', y que puede considerarse como una remercantilización de la vida cotidiana; remercantilización, no 
lo olvidemos, que duplica la ocurrida en la administración (Offe 1988). Parece como si tras la necesidad de protección por parte de un estado estructurador de la colectividad y 'educador' de los individuos, sea ahora el mercado el que haya surgido de nuevo apoyándose y apoyando la orientación social del utilitarismo como componente substancial de la individualidad. Con la salvedad de que aunque la individualización afecta a la sociedad en su conjunto por medio del aburguesamiento de las clases bajas y menos favorecidas, beneficia directamente a un sector concreto de la clase media y las clases altas. Por ello, es dable afirmar que el abandono 'económico' del bienestar se apoya en el carácter prescindible con el que es interpretado y sentido su presencia en la vida cotidiana, económica social y cultural, para una clase social -la clase social media- que tradicionalmente había sido protegida y había surgido y prosperado gracias a su dinámica institucional. Muñoz del Bustillo (1989) lo describió con una claridad meridiana:

"Es posible que el proceso de crecimiento económico sostenido experimentado en las últimas décadas haya ampliado el número de los que pueden hacer frente, de forma individual y a través del mercado, a estas necesidades. Los sujetos con rentas medias altas y altas -aristocracia obrera, profesionales liberales, burocracia administrativa y directivos altos y medios- pueden, y de hecho lo hacen, acudir al sector privado para cubrir sus necesidades de educación, sanidad y seguridad, con unos mayores niveles de comodidad, selectividad y estatus social. Es lógico que desde estos grupos, y desde las ideologías políticas que les representan, se empiecen cuestionar el mantenimiento de un Estado de bienestar en cuya financiación colaboran y del que no se benefician, puesto que cuentan con vías alternativas de cobertura más satisfactorias" (50)

\begin{tabular}{|c|c|}
\hline CÓDIGOS DE & CÓDIGOS DE LA MODENIDAD \\
LA SEGUNDA & \\
MODERNIDAD & Menor poder Infraestructural/ \\
\hline Regulación Flexible & Mayor poder despótico interno \\
(Desregulación & Mayor presencia de organizaciones supranacionales \\
Supranacional) & Globalización del Mercado/Monetarismo \\
\hline Mercado Global & ECONOMÍA FINANCIERA \\
(Economía Financiera) & Toyotismo / 'Just in time' / Producción sin excedentes / \\
& Desregulación del trabajo / Producción en Grupo / Adaptabilidad/ \\
& Adhocracia / Culturas Colectivas Fuertes/ \\
& Culturas Empresariales /Centralización de los Objetivos de \\
Producción/ Descentralización de los medios y procesos \\
Separación Grupos de Decisión y Grupos de Operación \\
Incremento del Sector de Servicios \\
\hline Consumidor & Los derechos del consumidor por encima del ciudadano \\
& Individualismo posesivo \\
& Pérdida del Ámbito Público \\
(Democracia limitada) & Déficit democrático/ Democracia Elitista \\
& Fragmentación Cultural \\
& Segmentación Social \\
& (Desigualdad) \\
\hline
\end{tabular}

Tabla 2. Características de la segunda modernidad (neoliberal). Fuente: Elaboración propia 


\section{EXCURSUS. EL PENÚLTIMO ACTO}

There is no alternative Margaret Thatcher

Trichet: 'The market is always right. And it has to be fully respected at all times.' Question: 'I am sorry, you said that the market is always right?"

Trichet: 'Yes, I said the market is always right. Jean-Claude Trichet en una conferencia de prensa el 8 de Abril de 2010

Una de las conclusiones que podemos entresacar de lo que acabamos de analizar, es que son las clases medias, que fueron aupadas y apoyadas por el estado de bienestar, quienes abandonan el terreno del bienestar, sintiéndose suficientemente fuertes como para abrazar el mercado, en tanto nuevo terreno de actuación social y política. Lo que no imaginaron es que abandonando el ámbito del bienestar, abandonaban también lo que como colectividad les dio sentido público: la ciudadanía. Antes de adentrarnos en las implicaciones de dicha pérdida, que es, repitámoslo, primero del ámbito público y, segundo, en tanto tal, del ámbito ciudadano, quisiéramos exponer, brevemente, las oleadas políticas que podemos detectar en este proceso, de la mano de Steger y Roy (2011). Este planteamiento nos ayudará a entender con más precisión el contexto en el que se está produciendo actualmente la pérdida de lo público.

Steger y Roy (2011) han identificado fundamentalmente dos. La primer se produce entre finales de los setenta y principios de los ochenta, con la llegada al poder en Inglaterra de Margaret Thatcher (1979-1990) y en los Estados Unidos de Norteamérica de Ronald Reagan (1981-1988). Durante sus mandatos es cuando comenzaron a activarse los códigos que introdujeron en la vida cotidiana el neoliberalismo como forma de vida. Pero, dicha introducción no fue ni plena ni exenta de titubeos; sí fue ejemplar y notoria en cuestiones como la reducción del estado, la extensión de la economía financiera y la privatización creciente de sectores relacionados con servicios y derechos sociales (Steger y Roy 2011: 44). ${ }^{8}$

Tras esta primera, la segunda oleada vino de la mano, curiosamente, de partidos no claramente neoliberales; nos referimos al acceso a la presidencia norteamericana de Clinton y en Inglaterra del 'laborista' Tony Blair. Si el primero consolidó la idea de mercado global, que vino a substituir a la de neoliberalismo; el segundo continuó con la política económica de su antecesores torys enmascarándola en la así denominada tercera vía, una manera de suavizar la desregulación neoliberal, manteniéndola. ${ }^{9}$

Sin embargo, el neoliberalismo sigue vigente. No sólo porque, por ejemplo, tanto en Norteamérica, como en Europa, existen gobiernos conservadores, sino porque la política neoliberal actual posee una fuerza arrasadora mayor de lo que se hubiera podido imaginar hace unos años y, especialmente, tras el crack de 2008. Efectivamente, la crisis del mercado de hipotecas y con él parte de la banca norteamericana, ${ }^{10}$ puso al sistema

\footnotetext{
8 Steger y Roy (2011: 85) hacen notar que ni Reagan ni Thatcher redujeron el gasto militar.

9 "La Tercer Vía supone un equilibrio entre la regulación y la desregulación, tanto en el ámbito transnacional como en los niveles nacional o local” (Giddens, 1989). Aunque Steger y Roy (2011) analizan la extensión del neoliberalismo a Latinoamérica y a Asia.

10 Como indican claramente Steger y Roy (2011), Alan Greenspan "permitió que las compañías bancarias pudieran poseer como afiliados bancos de inversión" (199).
} 
económico mundial en una situación cercana a la bancarrota. La alternativa vino esta vez del gobierno en forma de rescate de la banca.

"Algunas de las instituciones financieras más importantes y reverenciadas, aseguradoras y entidades suscriptoras de préstamos hipotecarios avaladas por el estado, como Lehman Brothers, Bear Stearns, Merril Lunch, Goldman Sachs..., o bien se declararon en bancarrota o tuvieron que ser recatadas por lo que ha sido el más espectacular giro hacia la nacionalización que jamás se haya visto en (Norte)américa desde la época de la Gran Depresión” (198)

Parecería, en un análisis superficial, que se estaba no sólo contradiciendo los principios esenciales del neoliberalismo (no intervención del estado), sino que el mismo neoliberalismo estaba acabado y tendría que ser substituido por un proceso de férrea regulación; como incluso sugirió el primer ministro australiano Kevin Rudd (2009). ${ }^{11}$ Lo que sucedió fue lo contrario. El estado acudió con fondos públicos -es decir, con fondos pertenecientes a todos los ciudadanos y ciudadanas- para salvar y rescatar a las maltrechas entidades financieras y bancarias, que habían prosperado en un ambiente de desregulación, libertad de mercado plena y de privatización y reducción de servicios sociales y ciudadanos.

"Los generosos paquetes de rescate lo único que consiguieron fue permitir que los fuertes conglomerados financieros gastaran aún más dinero, sin tener que declararse en bancarrota. El coste que han pagado los contribuyentes de todo el mundo es verdaderamente abrumador: las generaciones futuras tendrán que responder a los billones de dólares que se han utilizado para financiar estos programas" (Steger y Roy, 2011: 199-200).

\begin{tabular}{|c|}
\hline Oleadas Neoliberales \\
\hline Primera Oleada (80-90) Privatización, ideología del Mercado y Política \\
Monetarista \\
\hline Segunda Oleada (90-2007) Globalización del Mercado \\
\hline Tercera Oleada (2008 -) Ajustes Fiscales. Neoliberalismo Depredador. \\
\hline
\end{tabular}

Tabla 3. Oleadas neoliberales. Fuente: Elaboración propia a partir de Steger y Roy (2011)

Esto es justamente lo que queremos enfatizar. Primero, el neoliberalismo está asentado fuertemente en nuestros países (y no menos en Europa) y goza de una estupenda salud. Como ha remarcado un informe reciente del European Trade Union Institute (Lehndorff, 2012): "aunque se cuestiona retóricamente el fundamentalismo del mercado libre (freemarket), el neoliberalismo está siendo resucitado, a pesar del fuerte sentimiento público de que aquéllos responsables de la crisis deberían pagar las facturas" (Ibíd., 16); algo que no está, ciertamente, ocurriendo.

Segundo, no se trata ahora de un neoliberalismo exclusivamente orientado por los intereses que animaron a los gobiernos que condujeron la política económica desde los 80; se trata de un neoliberalismo más contundente y egoísta. La conversión de deuda privada (de los bancos, las financieras y las empresas) en deuda pública lleva a Annamaria

11 InsideJob es un 'documental' excelente, para entender la crisis, sin miramientos con los políticos que nos condujeron a ella. Ha sido dirigido por dirigido por Charles Ferguson en 2010. 
Simonazzi a afirmar que se trata de reemplazar un estado de bienestar por el bienestar de la banca ('welfare being replaced by bankfare'), ${ }^{12}$ y para Wickham se trata de un claro intento de proteger el 'socialismo para los ricos'. A nuestro juicio, la situación es todavía más radical. Nos encontramos en un neoliberalismo depredador: de fondos públicos, de presupuestos públicos y de vida pública.

Tercero, es cierto que algunas voces, incluso desde filas nada radicales, han advertido de la necesidad de que los estados y las instituciones supranacionales (como la Unión Europea), creen mecanismos de regulación económica (Eppler, 2009; Ryan, 2012). ${ }^{13}$ Pero estamos asistiendo justamente a lo que Todorov (2012) denomina 'neoliberalismo de estado'. Es el estado mismo el que participa en la política neoliberal que está arrasando las finanzas públicas y clausurando servicios sociales y asistenciales. ${ }^{14}$ Dicho de otra manera, es el estado mismo el que pone al servicio de intereses del mercado los presupuestos y los bienes públicos, que es como decir la vida de sus ciudadanos.

Cuarto, la democracia ha estado ligada a la idea de espacio público político y a la expresión de la voluntad política a través de la participación de los ciudadanos y ciudadanas. Perder espacio público supone perder democracia. Hace algunos años Estefanía $(2002)^{15}$ advirtió sobre este peligro en referencia -entonces- a la globalización triunfante: "Si la globalización depende más de los mercados que de las decisiones de las personas (directamente o a través de los representantes libremente elegidos), se pone en cuestión el concepto mismo de democracia tal y como lo conocemos"(20).

Dicho de otra manera, y en relación a lo que estamos indicando: si bien el neoliberalismo ha sido refractario a la voluntad democrática, asistimos actualmente a un constante apartamiento y socavamiento de la misma ${ }^{16}$ (Brown, 2005; Robertson, 2008; Todorov, 2012) y a un crecimiento espectacular de control de las corporaciones (Vitali et al., 2011). Al fin y al cabo, eso que llamamos los mercados no es otra cosa que una red de corporaciones: grupos empresariales y financieros, con nombres y apellidos.

\section{SALIDA Y VOZ EN EL SISTEMA EDUCATIVO}

Albert Hirschman (1977) ha desarrollado un enfoque sobre las organizaciones empresariales que -paradójicamente- puede servirnos para comprender la idea de lo público que quisiéramos enfatizar. Para dicho autor exiten dos estrategias básicas cuando una organziación empresarial está en declive: la salida y la voz. La primera es la típica respuesta económica y de mercado: "el cliente insatisfecho con el producto de una empresa que se pasa a otra, utiliza el mercado para defender sus bienestar o mejorar su posición"; la segunda es, por el contrario, una respuesta política -es la respuesta política por

12 Focalizarse en la deuda pública más que en la desigualdad, secundada por un énfasis en recortes en los gastos y la subida de impuestos (algo poco neoliberal, sea dicho de paso), es realmente el más claro indicador de lo que Wickhan (2012), denomina 'paradojas del no aprendizaje'.

13 Algo que repite incluso el Club de Roma. Véase von Weizsäcker, Young, Oran R. and Finger, Matthias (2005).

14 En algunos casos dicho 'neocapitalismo de estado' fomenta el nepostimo y la corrupción, como ha ocurrido y ocurre en España.

15 Véase también del mismo autor Estefanía (1998).

16 Un caso explícito en el que se sitúa a la democracia ciudadana como un peligro se encuentra en Hutchinson (1975). 
excelencia, afirma Hirschman (1977: 24). La voz es "un intento por cambiar un estado de cosas poco satisfactorio, en lugar de abandonarlo, mediante la petición individual o colectiva a los administradores directamente responsables, mediante la apelación a una autoridad superior con la intención de forzar un cambio de adminsitración, o mediante diversos tipos de acciones y protestas. Incluyendo las que tratan de movilizar la opinión pública (Ibíd:: 36).

Es fácil imaginar que lo que hace la política económica neoliberal es introducir en la vida pública opciones de salida; subvirtiendo y socavando cualquier opción de voz. Dicho de otra manera: la política neoliberal llevada a la educación aspira a establecer, defender y ampliar las opciones de salida de los clientes del servicio, favoreciendo las posibilidades del mercado educativo. De esta manera, tal como indicaron Freedman y Freadman (1980) y teóricos neoliberales de la educación como Chubb y Moe (1990), al aumentar las posibilidades de elección del consumidor, se amplia la calidad de la educación (Labaree, 2000: 115). De esta manera la educación es una mercancía; un servicio/ producto que puede ser comprado y vendido en el mercado.

Labaree (2000: 117) se apoya en un esclarecedor cuadro del mismo Hirschman (1977: 119), para indicar con mayor precisión lo que está ocurriendo a la educación pública norteamericana y por extensión a la casi totalidad de los sistemas de educación general.

\begin{tabular}{|c|c|c|c|}
\hline \multirow{4}{*}{$\begin{array}{c}\text { La organización es } \\
\text { sensible a }\end{array}$} & \multicolumn{3}{|c|}{ Cuando el declive suscita fundamentalmente } \\
\hline & & SALIDA & VOZ \\
\hline & SALIDA & $\begin{array}{c}\text { Organización } \\
\text { Competitiva / } \\
\text { Empresas } \\
1\end{array}$ & $\begin{array}{c}\text { Organización } \\
\text { donde la salida es } \\
\text { dificil y se permite } \\
\text { el disenso pero } \\
\text { inefectivo } \\
2\end{array}$ \\
\hline & VOZ & $\begin{array}{l}\text { Organización } \\
\text { (púboica) } \\
\text { donde la salida } \\
\text { es la primera } \\
\text { respuesta. } \\
3\end{array}$ & $\begin{array}{l}\text { Organizaciones } \\
\text { democráticamente } \\
\text { responsables } \\
4\end{array}$ \\
\hline
\end{tabular}

Tabla 4. Adaptado según los esquemas de Hirschman (1977: 119) y Labaree (2000: 117) 
Labaree (2000) señala que la celda 1 representa típicamente a una empresa o corporación, mientras que la 4 vendría representada por una organización política. Ambas formarían dos extremos de un continuo en el que se situarían las otras celdas: la 2 estaría ocupada por organizaciones con tendencia monopolista; i.e. organizaciones en las que para los clientes no hay posibildad de salida, por lo que se verían obligados, en términos del propio Hirschman (1977), a recurrir a algún mecanismo de cambio interno. Por último, en la casilla 3 estarían las organizaciones sensibles a la voz, pero que provocan respuestas de salida frente a la crisis por parte de sus usuarios. Y ésta es la situación de muchos sistemas educativos, pero especialmente el nortemericano (Labaree, 2000: 117).

A pesar de las connotaciones economicistas que presenta el esquema y las mismas argumentaciones de Hirschman (1977) y Labaree (2000) -si bien alejadas ambas de los postulados del neoliberalismo-, da la impresión de que el cuadro nos plantea una situación de elección individual; lo que es un error. Por ejemplo, el que los centros públicos de enseñanza estén en la casilla tres, no es una opción de los mismos centros; es, en definitiva, el resultado de una política educativa que, a su vez, se rige por una política económica neoliberal. Es más, y este punto es algo que el propio Laberre (2000: 119) reconoce, la política económica del neoliberalismo no sólo sitúa a los centros públicos en la casilla 3, sino que amplifica el sistema educativo según los patrones de la celda 1; es decir, aumenta la privatización aumentando la presencia de centros privados y presiona sobre los centros públicos para que adopten fórmulas privadas y empresariales. Éste es, justamente, el panorama en el que nos encontramos.

Pero, ¿qué significa realmente la opción de voz para lo público? La opción de voz representa el dominio público, que no es, como señala Marquand (2004) un 'sector', sino una dimensión de la vida social. "Simbólicamente -añade- está unido a la noción de interés público, distinto -en principio- del interés privado- y a los valores de ciudadanía, equidad y servicio. En él sus 'bienes' son distribuidos en razón de la necesidad, no de conexiones personales o según el acceso a recursos económicos. Es un espacio protegido del mercado y del dominio privado, donde los sujetos que no se conocen, se encuentran como partners iguales en la vida común de la sociedad- un espacio para formas humanas de desarrollo, que no pueden ser compradas en el mercado o encontradas en la estrecha comunidad del clan o en la familia o en el grupo de amigos íntimos" (27).

\section{LO PÚBLICO Y SU MERCANTILIZACIÓN}

Desafortunadamente, esta manera de entender lo público no es justamente la que las políticas y el pensamiento neoliberal están dispuesto a aceptar o a consentir. Y es por ello que dichas políticas presionan para que el sistema educativo se recoloque entre la casilla 1 y la 3; es decir, esté ampliamente formado por un sector de centros privados (para las élites) y un sector de centros estatales transformados según patrones del mercado (Labaree, 2000; Ravitch, 2010), para la clase media, normalmente preocupada por un futuro ventajoso para sus hijos e hijas.

"Cuando el sistema escolar se encuentra presionado para proveer a los consumidores individuales de un bien privado que les dará una ventaja competetitiva en la carrera por los buenos empleos, el estatus social y una vida confortable, dicho sistema se tiene que adaptar de tal manera que minará los beneficios públicos de la educación” (Labaree, 2000: 121-122). 
Detengámonos un poco más en este punto. ¿Qué opciones deja y qué modelos pone en funcionamiento la presión neoliberal al sistema educativo? Como acabamos de indicar, la casilla 1 es determinante y ha sido siempre una constante: casi todos los sistemas educativos tienen una presencia más o menos importante de centros privados. El problema es que un sistema educativo de cualquier nación no puede satisfacer las necesidades educativas únicamente con centros privados. Primero, porque no siempre es directamente rentable extender este tipo de centros más allá de los sectores privilegiados; segundo, porque las élites exigen sus propio sistema escolar, dentro del sistema escolar nacional; tercero, porque existen fórmulas indirectas -casilla 3- de reconvertir el sistema escolar estatal en un cuasi-mercado (Whitty, 1997; Apple, 2002; Laval, 2004; Torres, 2007; Ravitch, 2010). ¿Cuáles son esas opciones?

Ravitch (2010) y, con anterioridad, los trabajos de Whitty (1997) y Witty, Power, y Halpin, (1999), ${ }^{17}$ nos permiten reconstruir las opciones básicas con las que el mercado fractura y se apropia del espacio público. Ravitch (2010) enfatiza que el lema esencial es el de elección escolar (school choice) o elección de centro, tal como viene consignada por Chubb y Moe (1990). En una situación de mercado educativo, el elemento clave para ser protegido es la ampliación de las posibilidades que tienen las familias de elegir el centro de su interés, en un contexto marcadamente mercantil en el que los centros compiten para atraer a la clientela familiar. Cuando hablamos de un contexto mercantilizado, no nos referimos tanto a los centros privados de la casilla 1 que, como decíamos antes, han sido y son un sector permanente de la escolaridad orientada a las élites. La reforma propuesta por Chubb y Moe (1990), que se apoya ideológicamente en los postulados neoliberales de Friedman y Friedman (1980), pretende ampliar la 'elección' tanto a las clases medias como a las clases bajas, y a los centros escolares que recogen a ambas poblaciones. ${ }^{18}$

La elección escolar se ha materializado en tres versiones: cheques escolares, escuelas gestionadas privadamente y escuelas charter (o escuelas a la carta). Ravitch (2010: 121) señala, tomando como referencia la experiencia Norteamericana, que todos estos tipos de escuelas "recibieron fondos públicos para educar a los estudiantes aunque no eran escuelas estatales ni estuvieran dirigidas por una agencia gubernamental". El cuadro siguiente explicita la característica más sobresaliente de cada modalidad.

17 Véanse también Angulo (1997), Shipps (2000), Apple (2002), Torres (2007), Ball y Joudell (2007) McCarthy et al. (2009) y Saltman (2009)

18 Para no complicar excesivamente el panorama, hemos optado por no incluir dos variantes de la privatización escolar indicadas en el informe de Ball y Joudell (2007: 8). La privatización 'exógena' tiene que ver con "la apertura de los servicios de educación pública a la participación del sector privado, a través de modalidades basadas en el beneficio económico, y la utilización del sector privado en cuanto a la concepción, la gestión o la provisión de diferentes aspectos de la educación pública"; la privatización 'endógena' con la importación de ideas, métodos y prácticas del sector privado a fin de hacer que el sector público sea cada vez más como una empresa y crecientemente comercial". 


\begin{tabular}{|c|c|c|}
\hline Modalidad & Características & Estrategia \\
\hline $\begin{array}{l}\text { Cheque (vale) } \\
\text { Escolar }\end{array}$ & $\begin{array}{l}\text { Escuelas Privadas. El alumnado se matricula en } \\
\text { ellas por elección utilizando un vale/cheque que } \\
\text { procede de fondos públicos. Dicho vale/cheque } \\
\text { cubre normalemente una parte de la matrícula. }\end{array}$ & Salida $\underset{1}{\longleftrightarrow}$ Salida \\
\hline $\begin{array}{c}\text { Escuelas } \\
\text { gestionadas } \\
\text { privadamente } \\
\text { (Privately } \\
\text { Managed } \\
\text { Schools) }\end{array}$ & $\begin{array}{l}\text { Escuelas estatales (públicas) que son dirigidas } \\
\text { por una entidad externa que opera bajo contrato } \\
\text { con la administración local o estatal.Gestionadas } \\
\text { por corporaciones con ánanimo o sin animo de } \\
\text { lucro (algunas religiosas). }\end{array}$ & $\begin{array}{c}\text { Voz } \rightarrow \text { Salida } \\
3\end{array}$ \\
\hline $\begin{array}{c}\text { Escuelas a la carta } \\
\text { (Charter Schools) }\end{array}$ & $\begin{array}{l}\text { Reciben fondos públicos (también donaciones } \\
\text { privadas), pero están gestionadas privadamente. } \\
\text { La organización privada asume la gestión de la } \\
\text { escuela durante un perído concreto. No están } \\
\text { sometidas a las reglas y las regulaciones de las } \\
\text { escuelas estatales. Orientadas a la producción de } \\
\text { ciertos resultados. Pueden ofrecer un curriculum } \\
\text { especializado (artes, formación profesional, } \\
\text { matemáticas y ciencias) }\end{array}$ & $\begin{array}{c}\text { Voz } \rightarrow \text { Salida } \\
3\end{array}$ \\
\hline
\end{tabular}

Tabla 5. Modalidades de privatización del sistema escolar. Fuente: Elaboración a partir de Ravitch (2010), Whitty (1997), Witty, Power, y Halpin, (1999) y Carnoy (1997, 1998)

Como Ravitch enfatiza, de las tres modalidades, las escuelas a la carta, son la joya de la corona del movimiento de elección escolar (2010: 132). En norteamérica, como también está ocurriendo allí donde se ha aplicado y se aplica Whitty (1997) y Witty, Power, y Halpin, (1999) y Carnoy $(1997,1998),{ }^{19}$ dicha modalidad de escuela es aceptada por un amplio espectro de personas, "tanto de la izquierda, como de derecha y de centro, que ven en dichas escuelas a la carta... el antídoto contra la burocración y la paralización y como el cambio decisivo que revolucionará la educación Norteamericana y mejorará los resultados educativos" (Ravitch, 2010: 133).

Lo que Ravitch olvida indicar es que ni en Norteamérica ni en otros países, se trata, de que los grupos sean más o menos progresistas; sino que se trata, en realidad, por volver al terreno marxista, de su situación de clase. "La implementación de un plan de vales escolares que permita a las familias enviar a sus hijos e hijas a escuelas fueras de su vecindario o un plan para regular escuelas a la carta que sirva en nichos de mercado

19 Carnoy analiza expresamente Chile y Suecia y Whitty Inglaterra, Nueva Zelanda y Norteamérica; Ravitch se centra exclusivamente en Norteamérica. 
en distritos de escuelas públicas es una decisión política, que trabaja a favor de ciertos grupos más que de otros" (Carnoy, 1997:114).

Como indicamos en un apartado anterior, dado que las clases altas siempre han dispuesto de un sistema a su medida, han sido, las clases medias e incluso las clases bajas, que quieren ascender en la pirámide económica, quienes lo han abrazado, estimulado y defendido. Éste ha sido y continúa siendo un terreno abonado para que las corporaciones empresariales, el capital financiero e incluso organizaciones fundamentalistas y religiosas, participasen en el proceso de mercantilización educativa (Apple, 2002).

Llegados a este punto tendríamos que preguntarnos si la adopción de patrones de mercado ha supuesto un cambio tan positivo y benéfico tanto para el sistema en su conjunto como para sus usuarios, como suelen pregonar sus defensores (Chubb y Moe, 1990).

En su exhaustivo trabajo, Whitty (1997) afirma que los estudios revisados por él indican claramente que "perseverar en la mercantilización no genera mayores mejoras en la calidad de la educación y provocar casi con total certeza efectos daniños a la equidad"; y añade: "la amplia conclusión a la que llegan los estudios parece decir que aunque la retórica de la reforma sugiere que la mano oculta del mercado producirá los mejores resultados posibles, la realidad sugiere que es improbable que ése sea el caso" (35) A la misma conclusión ha llegado Carnoy $(1997,1998)$, cuando afirma que no existe evidencia suficientemente persuasiva de que las escuelas privadas son más efectivas que las públicas (Carnoy, 1997: 114).

Ravitch (2010: 146), trece años después, vuelve a repetir casi las mismas palabras: "existe poca evidencia de que las escuelas a la carta sean genéricamente mejores que las escuelas públicas. Ningún informe afirma que todo el sector entero de escuelas charter tenga éxito, y que cualqueir escuela charter sea mejor que una escuela pública".

Una investigación reciente llevada a cabo en la Universidad de Stanford (CREDO, 2009), en 2403 escuelas a la carta y en 15 estados revela que "sólo el 17\% de las escuelas a la carta (EC), analizadas ofrecían oportunidades educativas superiores para sus estudiantes; cerca de la mitad, un 46\%, lograban resultados no muy diferentes que los de las escuelas públicas locales, y un $37 \%$, resultados peores que los que hubieran obtenidos sus estudiantes si se hubieran quedado en escuelas públicas tradicionales". Unos resultados realmente decepcionantes en razón de los fondos derivados y de la alaraca neoliberal que ha encumbrado estas reformas. Estos resultados no confirman la idea de que la mercantilización de los sistemas educativos consigue mejorarlos.

A nuestro juicio, la mercantilización, especialmente en el contexto económico actual (la tercera ola neoliberal), tiene tres objetivos claros:

Primero, favorecer a sectores de clase alta y media, en detrimento de sectores sociales menos favorecidos. Este es un objetivo tradicional desde los años noventa en todas las reformar mercantilizadoras. Con ello, la segmentación social y la distancia interclase, se incrementa; incrementándose la injusticia educativa y social (Whitty, 1997; Apple, 2002; Paraskeva, 2008, 2011).

Segundo, relegar el sistema público a los márgenes de la sociedad (por utilizar la expresión de Bourdieu, 1999), como una forma de desagüe para todo aquel alumnado que o bien haya fracasado en el sistema bajo al influencia del mercado o bien no haya sido admitido en dicho sistema o que por su situación geográfica y aún económica no puede optar a él. Ello representa para Diane Ravitch (2010: 136) el gran dilema de la 
educación pública: tener que admitir a todo el alumnado, incluso a aquél que no quiera ser educado.

Tercero, la mercantiliación, al contrario que en los años 90, está sirviendo para derivar enormes fondos públicos a la iniciativa privada (Ravitch, 2010). Este es un proceso claro de depredación del sistema público, que merecería un análisis más detallado del que podemos prestarle aquí. Se trata, sin duda de un rapto, de un secuestro de los bienes públicos y, por extensión, de la escolaridad pública (Paraskeva, 2008, 2011).

El resultado tiene implicaciones políticas, sociales y culturales mucho más importantes de lo que podamos imaginar, si nos quedamos en un plano neutral de análisis y si buscamos una comparación -siempre superficial- entre los rendimientos de una opción pública u otra privada (Ravitch, 2010); como suele ser la costumbre en muchos estudios comparativos, incluido el estudio de CREDO (2009). Estamos convencidos que se trata de un intento más por evitar ese, así denomiando, enemigo interno de las sociedad occidentales que Samuel Hutchingson (Crozier et al., 1975: 115) identificó en los setenta en su informe a la Trilateral: una sociedad altamente educada, movilizada y participativa.

Quizás deberíamos comenzar a pensar que lo público y muy especialmente las escuelas públicas no están, como cree Ravistch (2010: 136) en un dilema, están en su lugar abriendo sus puertas a todo alumno; porque eso es el destino de cualquier institución pública: servir a la ciudadanía. Quizás tendríamos que comenzar a defender que las escuelas públicas son un bien común, parte de la commonwelth (Ostrom 2000; Hardt y Negri 2009) que nos hace ciudadanos y que como tal substente la existencia -en palabras de Avisahi Margalit (2010)-de una sociedad civilizada y una sociedad decente, es decir, una sociedad en la que sus ciudadanos no se humillan y en la que no son humillados por las instituciones y las organizaciones públicas que deberían servirles.

\section{REFERENCIAS BIBLIOGRÁFICAS}

Aglietta, M. (1979). Regulación y Crisis del Capitalismo. La Experiencia de los Estados Unidos. México, D.F.: Siglo XXI.

Albarracín, J. (1991). La economía de mercado. Barcelona: Trotta.

Allen, J. (1992). Post-Industrialism and post fordism. En S. Hall, D. Held y T. Mcgrew, (eds.), Modernity and its futures (pp.169-220). Cambridge: Politiy Press.

Angulo, J. (1997). El neoliberalismo o el surgimiento del mercado educativo. En J. Angulo (Coord.) Escuela pública y sociedad neoliberal (pp.17-38). Madrid: Miño y Dávila.

Angulo, J. (2011). La educación y el curriculum en el espacio europeo: ¿internacionalizar o globalizar?. En J. Gimeno (comp.) (2011), Saberes e incertidumbres sobre el curriculum (pp.478-497). Madrid: Morata.

Apple, M. (2002). Educar "como Dios manda". Mercados, niveles, religión y desigualdad. Barcelona: Paidós.

Ball, S. y Joudell, D. (2007). Privatización encubierta en la educación pública. Bruselas: Internacional de la Educación.

Boli, J.; Ramírez, F. y Meyer, J. (1990). Explicación de los orígenes y el desarrollo de la educación de masas. En P. Altbach y G. Kelly (Comp.) (1990), Nuevos enfoques en educación comparada. Madrid: Mondadori.

Boyer, R. (1992). La Teoría de la Regulación. València: Alfons el Magnànim.

Bourdieu, P (1999 ). La miseria del mundo. Madrid: Akal. 
Braham, P. (1992). The division of labour and occupational change. En J. Allen, P. Braham \& P. Lewis (eds.), Political and economics forms of modernity (pp.275-314). Cambridge: Polity Press.

Brown, W. (2005). Critical essays on knowledge and politics. Princeton: Princeton University Press.

Bruno, I., Clément, P. y Laval, C. (2010). La grande mutation. Néoliberalisme et éducation en Europe. Paris: Éditions Syllepse.

Buchanan, J. y Wagner, R. (1983). Déficit del sector público y democracia. Madrid: Rialp.

Carnoy, M. (1997). Is privatization through education vouchers really the answer?: A comment on west credo. The World Bank Research Observer, vol.12, n.1, 105-16.

Carnoy, M. (1998). National Voucher Plans in Chile and Sweden: Did Privatizacion Reforms Make for Better Education. Comparative Education Review, vo.42, n.3, 309-337.

CREDO (2009). Multiple Choice: Charter School Performance in 16 States. Center for Research on Education Outcomes: Standford University.

Crozier, M.; Huntington, S. y Watanuki, J. (1975). The crisis of democracy. New York: New York University Press.

Chubb, J. \& Moe, T. (1990). Politics, Markets and Amercia's Schools. Washington, D.C.: The Brookings Institution.

Eppler, E. (2009). The Return of the State? London: The Global Policy Institute London Metropolitan University.

Estefanía, J. (1998). Contra el pensamiento único. Madrid: Taurus.

Estefanía, J. (2002).Hij@, ¿qué es la globalización? Madrid: Taurus.

Friedman, M. y Friedman, R. (1980). Libertad de elegir. Hacia un nuevo liberalismo económico. Barcelona: Grijalbo.

Gamble, A. (1994). Free economy and the Sorong state. The politics of thatcherism. London: Macmillan.

Giddens, A. (1989). La tercera vía. La renovación de la socialdemocracia. Madrid: Taurus.

Giddens, A. (1993). Consecuencias de la Modernidad. Madrid: Alianza.

Gramsci, A. (1980). Notas sobre Maquiavelo, sobre la Política y sobre el Estado Moderno. Buenos Aires: Nueva Visión.

Habermas, J. (1973). Problemas de legitimación en el capitalismo tardío. B.A. Amorrortu.

Hardt, M. y Negri, A. (2009). Commonwelth. El proyecto de una revolución del común. Madrid: Akal.

Harvey, D. (1989). The Condition of Postmodernity. An Enquiry into the Origins of Cultural Change. Cambridge: MA. Blackwell.

Hayek, F (1985). Camino de servidumbre. Madrid: Alianza Editorial.

Hirschman, A. (1977). Salida, voz y lealtad. México: F.C.E.

Hobsbawn, E. (2003). La era de la revolución. Barcelona: Editorial Crítica.

Hobsbawn, E. (2004). La era del capital. Barcelona: Critica.

Huntington, S. (1975). The United States. En M. Crozier, S. Huntington y J. Watanuki (1975). The crisis of democracy (pp.59-118). New York: New York University Press.

Laval, C. (2004). L'école n'est pas une entreprise. Le néo-libéralisme à l'assaut de l'enseignement public. Paris: La Découverte.

Laval, C. (2005). Per què l'escola no és una empresa? Ponencia presentada al ciclo "Debats d’educació". Barcelona: Fundació Jaume Bofill.

Labaree, D. (2000). No exit: public educatin as an inescapably public good. En L. Cuban \& D. Shipps (Eds.), Reconstructing the common good in education. Coping with intractable American Dilemmas (pp.110-129). Standford, Calif. Standford University Perss:

Lehndorff, Steffen (Ed.) (2012) A triumph of failed ideas. European models of capitalism in the crisis. Brussels. European Trade Union Insitute.

Lippietz, A. (1986). New tendencies in the International division of labor: regimes of accumulation and modes of regulation. In A. Scott \& A. Sttorper (eds.), Production, work, territory: the geograpnical anatomy of industrial capitalismo (pp.16-41). London: Routledge. 
Margalit, A. (2009). La sociedad decente. Barcelona: Paidós.

Marquand, D. (2004). Decline of the public. Cambridge: Polity Press.

McCarthy, C.; Pitton, V.; Kim, S. \& Monje, D. (2009) Movement and stasis in the neoliberal reorientation of schooling. En M. Apple. A. Wayne \& L. Gandin, The routledge international handbook of critical education (pp.36-50). London: Routledge.

MacPherson, C. (1970). Teoría política del individualismo posesivo. Barcelona: Fontanella.

Meyer, J.; Kamens, D. \& Benavot, A. (1992). (eds.) School knowledge for the masses. World models and national primary curricular categories in the twentieth century. London: The Falmer Press.

Mishra, R. (1992). El estado de bienestar en crisis. Pensamiento y cambio social. Madrid. Ministerio de Trabajo y Seguridad Social.

Muñoz del Bustillo, R. (1989). Economía de mercado y etado de bienestar. En R. Muñoz del Bustillo (Comp.), Crisis y futuro del estado de bienestar (pp.23-53). Madrid: Alianza.

Navarro, V. (1997). Neoliberalismo y estado de bienestar. Barcelona: Aril.

Offe, C. (1988). Contradicciones en el Estado de Bienestar. Madrid: Alianza

Osborne, D. y Gaebler, T. (1994). La reinvención del gobierno. La influencia del espíritu empresarial en el sector público. Barcelona: Paidós.

Ostrom, E. (2000). El gobierno de los bienes comunes. La evolución de las instituciones sde acción colectiva. México. F.C.E.

Paraskeva, J. (2008). Ideology, Culture and Curriculum. Rotterdam: Sense Publish.

Paraskeva, J. (2011). Conflicts in Curriculum Theory: Challenging Hegemonic Epistemologies (Education, Politics and Public Life). N.Y.: Palgrave Macmillan

Ravitch, D. (2010). The death and life of the Great American School System. Hoiw Testing and Choice are undermining education. New York: Basic Books.

Robertson, S. (2008). 'Producing' knowledge economies: the World Ba nd, the KAM, education and development. En M. Simons, M. Olssen \& M. Peters (eds.), Re-reading Education Policies: Studying the Policy Agenda of the 21th Century. Netherlands: Sense Publishers.

Rowan y Miskel (1999). Institutional theory and the study of educational organkzations. En J. Murphy y L. Seashore (eds.), Handbook of research on educational administration (pp.359383). San Francisco: Jossey-Bass.

Rudd, K. (2009). "The global financial crisis" The Monthly. http://www.themonthly.com.au/ monthly-essays-kevin-rudd-global-financial-crisis--1421 (consultado el 15 de Marzo de 2012)

Ryan, J. (2012). Do we need Credit Rating Agencies? Social European Journal. http://www.socialeurope.eu/2012/03/do-we-need-credit-rating-agencies/ (consultado el 15 de Marzo de 2012)

Salaman, G. (1992). Work desing and corporate strategoies. En J. Allen, P. Braham \& P. Lewis (eds.) (1992), Political and economics forms of modernity (pp.392-370). Cambridge: Polity Press:.

Saltman, K. (2009). Corporatization and the control of schools. En M. Apple. A. Wayne \& L. Gandin (2009), The routledge international handbook of critical education (pp. 51-63). London: Routledge.

Steger, M. y Roy, R. (2011). Neoliberalismo. Una breve introducción. Madrid: Alianza.

Shipps, D. (2000). Echoes of corporate influence: managing away urban school troubles. En L. Cuban \& D. Shipps (Eds.), Reconstructing the common good in education. Coping with intractable American Dilemmas (pp.83-105). Standford, Calif.: Standford University Perss:

Todorov, T. (2012). Los enemigos intimos de la democracia. Barcelona: Galaxia Gutenberg.

Torres, J. (2007). Educación en tiempos de neoliberalismo. Madrid: Morata.

Vitali, S.; Glattfelder, J. \& Battiston, S. (2011). The network of global corporate control. PLoS ONE 6(10): e25995. doi:10.1371/journal.pone.0025995

von Weizsäcker, E.; Young, O. \& Finger, M. (2005). Limits to Privatization: How to Avoid too Much of a Good Thing. London: The Roma Club. 
Wickham, J. (2012). After the party's over: the Irish employment model and the paradoxes of nonlearning. En S. Lehndorff (Ed.), A triumph of failed ideas. European models of capitalism in the crisis (pp.59-78). Brussels: European Trade Union Insitute:.

Witty, G. (1997). Creating Quasi-Markets in Education. Review of Research in Education, Vol. 22: $3-48$

Witty, G.; Power, S. y Halpin, D. (1999). La escuela, el estado y el mercado. Deleganción de poderes y elección en educación. Madrid: Morata. 